\title{
Creating prospective value chains for renewable road transport energy sources up to 2050 in Nordic Countries
}

\author{
Wessberg, Nina ; Leinonen, Anna ; Tuominen, Anu ; Eerola, Annele ; Bolwig, Simon
}

Published in:

International Foresight Academic Seminar: Participatory Foresight for Smarter Futures - From Design to Impact

Publication date:

2013

Link back to DTU Orbit

Citation (APA):

Wessberg, N., Leinonen, A., Tuominen, A., Eerola, A., \& Bolwig, S. (2013). Creating prospective value chains for renewable road transport energy sources up to 2050 in Nordic Countries. In International Foresight Academic Seminar: Participatory Foresight for Smarter Futures - From Design to Impact Zürich University of Applied Sciences, ZHAW. http://www.ine.zhaw.ch/en/engineering/institutes-centres/institute-of-sustainabledevelopment/events.html

\section{General rights}

Copyright and moral rights for the publications made accessible in the public portal are retained by the authors and/or other copyright owners and it is a condition of accessing publications that users recognise and abide by the legal requirements associated with these rights.

- Users may download and print one copy of any publication from the public portal for the purpose of private study or research.

- You may not further distribute the material or use it for any profit-making activity or commercial gain

- You may freely distribute the URL identifying the publication in the public portal 
International Foresight Academic Seminar in Switzerland, Sept 16-18, 2013

A Full Paper

\title{
Creating prospective value chains for renewable road transport energy sources up to 2050 in Nordic Countries
}

Nina Wessberg, Anna Leinonen, Anu Tuominen, Annele Eerola, VTT Finland

Simon Bolwig, DTU Denmark

\begin{abstract}
If the Nordic energy and transport sectors are to meet the 2050 energy and climate policy targets, major systemic changes are necessary. Along with new technologies, changes are required also in other societal functions such as business models and consumer habits. The transition requires cooperation between public and private actors. This paper discusses the paradigm change towards 2050 Nordic road transport system based on renewable energy. More precisely, it proposes an approach for creation and analysis of prospective value networks up to the year 2050. The value networks arise from three alternative, but partly overlapping technology platforms, namely electricity, biofuels and hydrogen. The approach outlined in the paper combines elements from the fields of system level changes (transitions), value chain analysis and forward looking policy design. It presents a novel, policy relevant application with a set of practical tools to support development of implementation strategies and policy programmes in the fields of energy and transport.
\end{abstract}

Keywords: Value networks, foresight, transport system, energy system, multi-level perspective, transition

Acknowledgements: The research work presented in this paper was carried out as a part of TOP-NEST (Nordic Pathways for Sustainable Transport and Energy) research project, under Nordic Energy Research Sustainable Energy Systems 2050 research funding programme, which is gratefully acknowledged. The authors also wish to thank all TOP-NEST project WP4 researchers: Lars Coenen (Circle Lund), Lars J. Nilsson and, Alexandra Nikoleris (Lund University), Antje Klitkou, Dorothy Sutherland and Eric Iversen (NIFU), Sara Ben Amer (DTU), Juhani Laurikko and Tiina Koljonen (VTT) for their valuable contribution.

\section{Introduction}

Sustainable energy technologies are driven especially by the climate change challenge, which necessitates paradigm shift also in global energy production and consumption structures. Currently, about $20 \%$ of the Nordic $\mathrm{CO} 2$ emissions are due to transport sector. If the Nordic energy and transport systems are to meet the 2050 energy and climate policy goals, a major transition is necessary. Along with new technologies, changes are required also in other societal sectors such as business models and consumer habits. The transition requires cooperation between public and private actors. Political decisions should create potential to enterprises which can provide renewable energy solutions in a way that they attract also consumers and transporters of goods. Wise political decisions are needed in order to attract all the important actors in the change process. 
In order to be able to make such wise political decisions we need foresight actions to get an idea about the future trends and needs, and possible ways of shaping the future. Technological systems, such as transport system, are socially constructed and shaped (Huges 1987). Because system is socially shaped we have an opportunity to create the future together (participative foresight). Hence, we believe that, for the most part, actors create the future and therefore the state of the transport system is a result of the measures and actions carried out by the producers, operators and users of the system. Therefore beside foresight actions we also need knowledge and understanding about the actors who are important in the change process. In our understanding actors are outlined in value networks.

In this paper the paradigm change towards a new sustainable and innovative energy system of 2050 is discussed in the context of road transport sector in the Nordic countries. The focus is on developing tools to understand, create and analyse prospective value networks up to the year 2050. With 'value network' we mean a network of activities needed in order to deliver a specific valuable product and service for the market, incl. activities related to energy sources or feedstock production; energy production; distribution and transportation; retail; consumption; regulation and governance; and research and development. In our case the value networks arise from three alternative, but partly overlapping technology platforms, namely electricity, biofuels and hydrogen. In addition, the prerequisites for the feasibility of the resulting value chains are considered. The motivation for the paper is to produce knowledge for future decision making and policy support in order to create enabling ground for sustainable energy solutions for the future transport sector. The proposed prospective value chain creation process seeks to identify the critical elements in the networks to be taken into consideration in strategic planning and decision making.

Traditionally value chains are considered in rather short term business opportunity analyses. In our case, we need to outline the value chains, or networks, in the far future. Hence, our research questions are more specifically:

- What are the essential elements of the process for creating and understanding the key dimensions in prospective value networks for renewable energy and transport systems?

- What are the needs and constraints in participatory foresight in the context of road transport energy systems development to support sustainable policy making?

The paper is based on TOP-NEST project, which is a Nordic Energy Research funded effort to explore three renewable energy technology platforms: 1) electricity systems, 2) liquid and gaseous biofuels, and 3) hydrogen systems, and the potential of the systems to give rise to new value networks, creating entrepreneurial opportunities in the road transport sector. .The focus of the paper is thus in value networks that are needed and/or expected to develop in these free platforms, and in possible synergies between these platforms. This paper describes preliminary results of the TOP-NEST prospective value chain process. The development work is continues.

\section{Theoretical background}

\subsection{The functions of foresight in policy-making}

The impact of foresight on policy-making has been discussed among foresight experts practitioners (e.g. Georghiou \& Keenan 2006, Da Costa et. al. 2008, Weber et.al. 2009, Könnölä e.al. 2009, 2011). One aspect 
of this discussion is to consider the functions of foresight in policy-making. The functions of foresight can be summarized into three major functions, which are 1) informing, 2) facilitation, and 3) guiding. These three functions are discussed briefly below.

Policymakers are dealing with increasingly complex issues that are highly interconnected and interdependent. They also need to take into account the multiple dimensions of issues, such as scientific and technological, cultural and social, political, economic, environmental aspects (Da Costa et al. 2008, Könnölä et al. 2009). There is also plenty of information, research material and reports available on matters, but the challenge is, how to make sense of it in the given timescale of policy-making. Therefore, there is serious need for policy advising, which can be described as transmitting complexity to policymakers. The special function of foresight is to provide this advice in future context. The informing function of foresight is, therefore, generation of insights regarding the dynamics of change, future challenges and policy options, along with new ideas, and transmitting them to policymakers as an input to policy conceptualisation and design (Da Costa et. al. 2008) or other words, generation of consolidated findings concerning the dynamics of change and future challenges and options (Weber et.al. 2009).

The second function, facilitation of policy implementation, gets it motivation from the changing nature of policy-making. There has been a shift in the conceptual understanding of policy process (Weber et. al 2009; Da Costa et. al 2008). The shift has been from linear models of policy-making, consisting of successive phases such as formulation, implementation and evaluation phases, into cyclic models, where evaluations are supposed to feed back into the policy formation and implementation phases. This kind of thinking puts more emphasis on interactions, learning, and decentralised and networked characters of political decisionmaking and implementation. The effectiveness of policy depends also on the involvement of a broader range of actors, and therefore also, the role of government shits from being a central steering entity to that of a moderator of collective decision-making processes. To meet the requirements of the new mode of operation, one needs some instruments. Foresight can be seen as such instrument. It builds common awareness, networks and visions among stakeholders, and provides a forum for various actors for interaction, cooperation and learning in relation to specific change or transition. Foresight processes promote the development of "future-oriented attitudes" among participants, and the possibilities for better informed choices increase, which makes them to better accept and encourage changes in the right direction. This process makes the implementation of policies smoother (Da Costa et al. 2008). Another aspect in the facilitation function of foresight is the possibility to embed the participation of civil society within the policy-making process, which improves the legitimacy of the policy-making (Da Costa et al 2008).

The third function, which is called policy guiding, refers to the capacities of foresight to support strategy formation or policy definition. Weber et al. (2012) describes this function as strategic counselling of the policy process, which is effected by integrating the future-oriented information generated in the foresight process with the perspectives of individual actors. Da Costa et al. (2008) use different expression. According to them, supporting policy definition implies that foresight translates anticipatory intelligence into options for policy definition. This function operates only if foresight process is carried out jointly with the policymakers in charge of the specific policy filed. To take this line even further, Da Costa et al. (2008) formulates another function for foresight, which is reconfiguring the policy system. Foresight exercises may bring to light the inadequacy of the current policy system to address the major challenges that society is facing. For example, they can draw attention to the inherent tension between the departmentalised government structures and "multi-dimensionality" of the issues. This is an important aspect in the context 
of this paper, as it integrates the perspectives of transport, energy and technology \& innovation policies, which are often located under different ministries in many countries.

In addition to the previous functions, Da Costa et al. (2008) list also symbolic function of foresight. By launching a foresight exercise policymakers may wish to signal to the public that their decision making is based on rational information. The reverse side of this is that it may hinder the policy informing impact, and foresight exercises can be undertaken with the sole aim of providing justification for a policy that has already been decided. It has also been pointed out that for the various main functions - informing, facilitation and guidng - foresight processes can be understood as means of knowledge management when dealing with highly interconnected complex issuers (Eerola \& Miles, 2011).

Ahlqvist et. al (2012) present a concept of forward-looking policy design. In their concept policy design refers to an adaptive and experimental approach in which a selected variety of policy instruments are applied either simultaneously or successively. The selection of instruments and their sequence of implementation may vary depending on the characteristics of the system under policy intervention. According to Ahlqvist et al., policy design aims to increase the resilience of the policy practices, because it allows space for policy experimentation as multiple policy instruments are adapted and tested in parallel. Foresight has a specific role in forward-looking policy design due to its functions, such as discussed above.

As was discussed above, there is a shared view on the potential of foresight in assisting policy-making. What does the analysis say about the impacts of foresight on policy-making? Könnölä et. al (2011) concluded based on their analysis of selected foresight projects that it is very difficult to trace the impacts of foresight on policy-making, as policymakers seldom refer to the sources they use in decision making. Almost all of the analysed projects produced consensual outcomes and lacked outcomes emphasising diverse future perspectives, which may lead to limited exploration of alternative future pathways, even if the latter aspect is often addressed as the strength of many foresight methods and approaches. The informative function of foresight was found to be clear in the analysis. However, the informative aspect of foresight projects may make it difficult to attract those participants who are the real decision makers. This way, foresight exercises may have only modes impact on real world policy-making. However, foresight experts and practitioners have developed various approaches and procedures to fulfil the expectation of foresight. For example, Adaptive Foresight (Eriksson \& Weber 2008) contributes especially to the strategy counselling function, and Innovation Policy Roadmapping (Ahlqvist et. al. 2012) to forward-looking policy design.

Our approach combines analysis of system level changes (transitions) and value chain analysis with foresight approach, in order to assist sustainable policy-making in the field of energy and transport. In this way, the paper also contributes to the literature discussed earlier in this chapter. Multilevel perspective to transition and theories on value chain analysis are further discussed in the following sections.

\subsection{Multilevel perspective to transition}

Change towards sustainable energy and transport systems in the climate change context is possible only through systemic innovations for example in the fields of renewable energy production, energy efficiency, energy saving, behavioural changes in energy consumption, etc. These innovations require changes in all system functions. It means that the whole societal system has to be opened up in order to find out the 
barriers and drivers for the innovative systemic change; decision makers in all levels, households, companies, schools, universities, ministries, parliament and other levels, should be involved.

Transition Management refers to an attempt to redirect the existing dynamics of technological change and the entire techno-economic and societal system. Transition management intends to clarify the content and challenges of systemic change and societal embedding of new innovations. In transition management approach the technological system, such as energy or transport system, is understood as being composed of physical technologies -in the form of components, combined systems and infrastructure, and social technologies (institutions) - in the form of culture, social patterns, constrains and mechanisms of behaviour such as social norms, routines, legislation, standards and economic incentive mechanisms. The Netherlands is among fore-runners in developing, applying and implementing transition management approach (see e.g. Geels 2005, Geels and Kemp 2007, Geels and Schot 2007).

A dominating essence of a complex technological system is path dependence, which highlights that directions for future development are foreclosed or inhibited by directions in the past development. Most innovations are built on past discoveries and needs to be adapted to pre-existing conditions for successful diffusion. The path-dependent and irreversible nature of techno-institutional co-evolution makes transitions difficult to achieve; the prevailing system acts as a barrier to the creation of a new system.

Beside the fact that existing technological solutions direct or stabilize the development of the system, technology developers often neglect the fact that stakeholders are often reluctant to adopt and adapt to new innovations. The understanding of the dynamics of social acceptance of new technologies is here of crucial importance since the intrinsic resistance of existing systems is often dominating and hindering systemic changes.

The transition in path-dependent system is a complex multidimensional societal change process, dealing with the co-evolution of technological, industrial, policy and social changes. A Multi-Level Perspective (MLP) framework has been developed first in the Netherlands (Geels 2005), in order to describe this complex process. The framework has also been developed and applied in UK (Foxon et. al. 2010). Geels has applied the MLP framework also to the transport system in his recent work as he has studied transitions towards low-carbon futures of automobile systems (Geels 2012).

Three levels of change are abstracted in the MLP model: landscape, regime and niche. Landscape, forms an exogenous macro level environment that influences developments in niches and regimes. General developments in global operating environment, including e.g. economic, cultural or environmental factors compose the landscape level. The socio-technical landscape only tends to change very slowly since for example demographic changes, macro-economics, and cultural changes are slow, possibly over generation changes.

Regime refers to the existing structures and actions of the system. In the context of this paper, these structures and actions are related for example to nuclear power or mode specific transport systems. The specific form of the regime is mainly shaped and maintained through the mutual adaptation and coevolution of its actors and elements. Path dependent planning and innovations based on existing solutions direct the almost stable system. Hence, the prevailing system acts as a barrier to the creation of a new system. 
Niches, in turn, form the level where radical novelties emerge. Niches are local innovative solutions, experiments. Niches may, for instance, take the form of small-market niches, where selection criteria are different from the existing regime. Survival of such niches may be supported by public subsidies and act as incubators for new technologies or practices. Niches provide opportunities for learning and incubation of alternative solutions that may gradually become strong enough to challenge the existing regime or adopt and transform the regime towards new directions. Niche level solutions give alternatives and options by performing social experiments of e.g. energy related innovations.

The system transition, which in our case aims towards renewable energy solutions in the Nordic transport sector in 2050, is possible if the change processes in all these different levels are synergetic. In other words, the socio-technical change is a result of the interaction and synergy of all the different levels. One single change cannot change the whole system, but a system innovation is needed. Old regime is transferred into new 2050 regime due to a system change affected by the landscape and niche level changes. This transformation is possible only if policy, regulation, markets, values, resources, strategies and technology are changed so that they boost the system into the same direction. Institutional factors, behaviour and energy infrastructure are also the key factors, which define the crucial elements for political decisions.

Basically, there are three complementary options to be considered towards low carbon transport systems. The first one is simply reduction of transport volumes. Land use and community structure has the closest correlation with the amount of passenger transport needed. The denser the structure the less motorised transport is needed. Furthermore dense structure provides a greater opportunity to walking, cycling provision for public transport. The amount of freight transport is also related to the regional structure and population density, but more to the framework of economy, business and industry (Koljonen and Similä 2012).

The second option is improvement of energy efficiency of transport. This means technological improvements in vehicle technology but also modal shifts from energy intensive modes, especially road transport, to more sustainable modes, such as rail transport.

The third path is the use of low carbon energy (with low carbon intensity) as a primary energy source for transport. The options for this are biofuels, electricity from renewable energy sources and hydrogen being among the promising options. In this paper, we focus here on the third path - use of low carbon energy - by exploring the potential of three renewable energy technology platforms, namely biofuels, electricity systems and hydrogen systems in the future (2050) Nordic energy and transport systems.

Energy Agency and Nordic Energy Research have predicted one potential pathway to a carbon neutral energy future (IEA/NER 2013). According to pathway, total energy use of transport sector drops slightly from 2010 to 2050. This is mainly due to positive developments in fuel economy of engines. The share of biofuels in transport energy production is predicted to increase significantly till the year 2050. Biofuel cars and electric vehicles are to be the main road transport modes and the share of rail transport both in passenger and freight transport is forecasted to increase steadily. The use of fossil fuels will diminish. The pathway suggests that the main passenger road transport mean in large cities of Nordic Society in 2050 will be electric vehicles, possibly integrated to smart transport concepts. The attitudes towards car ownership are expected to change towards car sharing.

The shift towards low carbon energy and transport future predicted by the pathway (IEA/NER 2013) will require systemic changes in all of the MLP levels and efforts from various energy and transport system 
actors. Further, the prospective alternatives for future renewable energy sources for transport need to be: (1) technologically feasible, (2) economically viable and (3) environmentally sound as regards the producers, users, infrastructure, vehicles, services and governance. For example in the final stage of the implementation, production, refuelling infrastructure, and or compatible engines and vehicles may set the limit.

\subsection{Value chain analysis ${ }^{1}$}

Global value chain (GVC) analysis has emerged since the early 1990s as a novel methodological tool for understanding the dynamics of economic globalization, international trade as well as particular industries such as automobile manufacturing (Sturgeon et al. 2008). (The term GVC in this article refers also to work known as 'global commodity chain' analysis from 1994 onwards). GVC analysis is related to but distinct from global production network (GPN) analysis (Coe et al., 2008); the latter has been developed mainly with economic geography and has a broader approach, e.g. in terms of inclusion of the institutional environment of value chains. GVC is based on the analysis of discrete 'value chains' where input supply, production, trade and consumption or disposal are explicitly and (at least to some extent) coherently linked. In addition to the descriptive aspects of territoriality and input-output structure, much GVC discussion has revolved around two analytical issues: how GVCs are governed (in the context of a larger institutional framework), and how upgrading takes place along GVCs. Many of these discussions have been concerned with how power and rewards are embodied and distributed along GVCs, what entry barriers characterise GVCs, and how unequal distributions of rewards can be challenged. The application of GVC to the context of technological innovation and renewable energy is novel and is attempted in the TOP-NEST project.

The use in GVC analysis of the term chain suggests a focus on 'vertical' relationships between buyers and suppliers and the movement of a good or service from producer to consumer. This entails an analysis centred on flows of material resources, finance, knowledge and information between buyers and suppliers (where 'upstream' signals flows towards production, and 'downstream' towards consumption). Processes of coordination and competition among actors operating in the same function or segment of a particular chain are given less attention. A node is the point in a value chain where a product is exchanged or goes through a major transformation or processing. A segment is a 'vertical chunk' of a value chain between two nodes, for example from production to export.

In traditional manufacturing network operations of suppliers, lead producers (such as OEMs - original equipment manufacturers) and customers are seen as independent sequential tasks, which form a value chain. Since the 1990s, however, this pattern has been changing and the theoretical discussion has also emphasised the transfer from value chains to value networks (Normann \& Ramirez 1994; Peppard \& Rylander 2006). Value network perspective is considered to be more suited, especially, to those organisations where both the product and supply and demand chain is digitized, such as banking, insurance or telecommunication. Figure 1 illustrates the need for new kind of collaborative approach within manufacturing networks. Still, in practice, co-operation of manufacturing networks is mostly limited to bilateral collaboration, e.g. vertical relationships between a customer and a supplier and the change towards network level decision making and operations is in the wind.

\footnotetext{
${ }^{1}$ This section is partly based on Bolwig et al (2010).
} 
As definitions, we may present the following (Valkokari et. al 2011):

- Value chain consists of entire sequence of activities or parties that provide or receive value in the form of products or services.

- Value network consists of organisations (companies) co-operating with each other to benefit all network members.

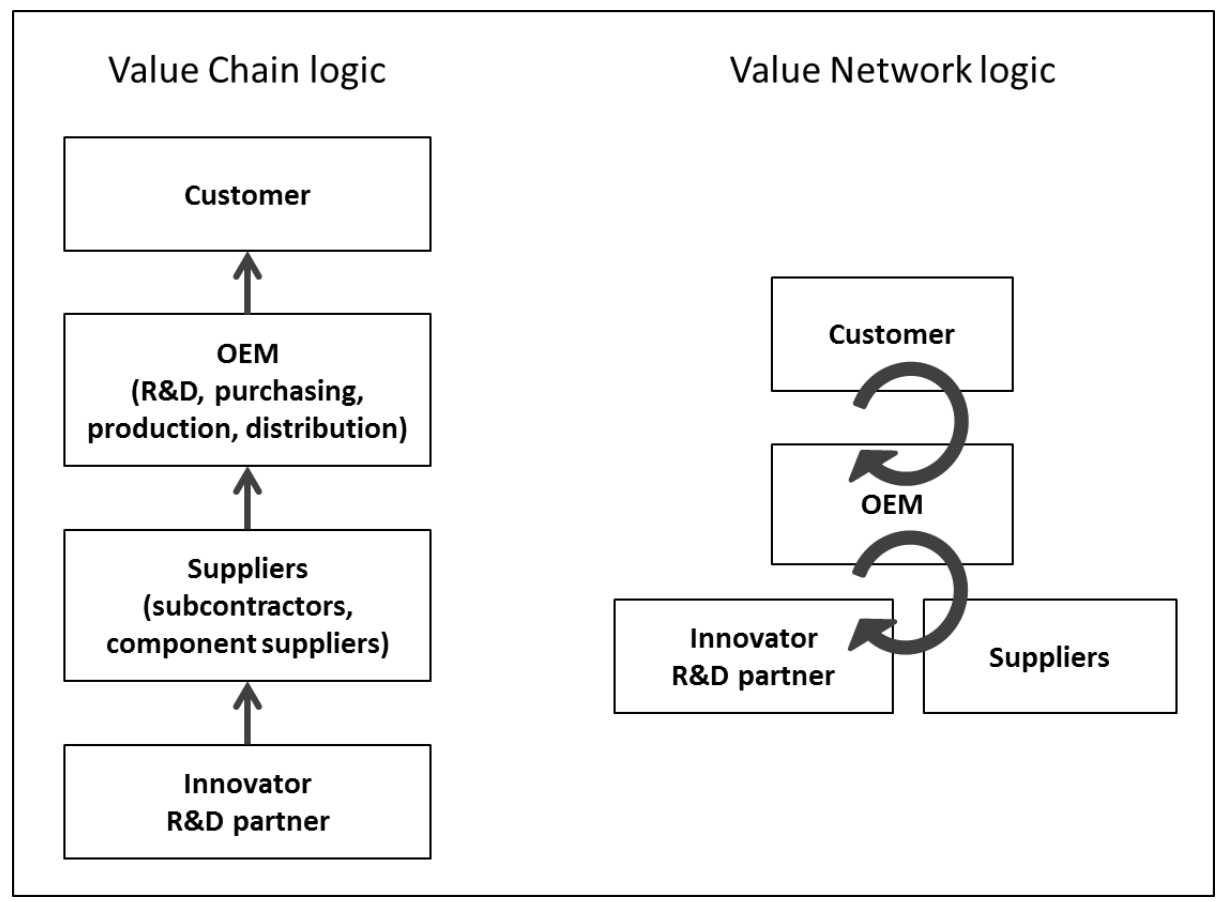

Figure 1. Changing paradigm from value chain to value networks.

In the value chain context, governance is the process by which so-called 'lead firms' (see below) organize activities with the purpose of achieving a certain functional division of labour along a value chain - resulting in specific allocations of resources and distributions of gains. It involves setting of the terms of chain membership, the related incorporation/exclusion of other actors, and the re-allocation of value-adding activities (Gereffi, 1994; Kaplinsky, 2000; Ponte and Gibbon, 2005; Gibbon et al., 2008). Lead firms are seen as not only dictating the terms of participation to their immediate suppliers, but also to be capable of transmitting these demands upstream, often all the way to primary producers.

Recent literature points out that external actors can have an important say in how a GVC is governed, e.g. governments, large NGOs, 'experts', certification bodies and service providers (Ponte, 2007; Riisgaard, 2009). External actors are often important in emerging industries like those for renewables. The literature also distinguishes between overall form of governance and forms of coordination between actors in different functional positions in a GVC, since there may be different forms of coordination in different segments of the same chain. Three major forms of coordination can be distinguished: (1) market (spot or repeated market-type inter-firm transactions where price is the dominant coordination mechanism), (2) hierarchy (vertical integration - when an actor performs several value chain functions), and (3) different 
kinds of contractualisation (between 'market' and 'hierarchy', denoting longer-term and more complex economic relationships between chain actors, as distinct from market transactions; for a different classification, see Gereffi et al., 2005).

In the context of this paper, we need to make a distinction between value chain analysis, in the meaning of analysing and developing of existing value chains, and the analysis of prospective value chains. For example, In GVC analysis the concept of upgrading is used to identify the possibilities for producers to 'move up the value chain', either by shifting to more rewarding functional positions, or by making products that have more value-added invested in them, and/or that can provide better returns to producers. The upgrading process is examined through the lenses of how knowledge and information flow within value chains (Gereffi, 1999). Upgrading is about acquiring capabilities and accessing new market segments through participation in particular chains. Humphrey and Schmitz (2002) have developed the following typology of upgrading:

1. process upgrading: achieving more efficient production through the reorganization of productive activities;

2. product upgrading: moving into products with increased unit value;

3. functional upgrading: changing functions to increase the skill content of activities;

4. inter-chain upgrading: applying competences acquired in one function of a chain in a different sector/chain.

As our approach is forward-looking and we want to anticipate value chains that may exist in long-term future, we need slightly different viewpoints. Value network approach provides us with an interesting ground. Peppard and Rylander (2006) present a procedure of Network Value Analysis (NWA), which takes the network-oriented model as a starting point. The aim of NVA is to generate a comprehensive description of where value lies in a network and how value is created. The analysis is based on step-wise procedure starting from network objectives definition and identification of network participants to the analysis of value dimensions and influences, and shaping of the final value network. In the beginning of the network analysis, one actor is taken as the network focal and then all the other actors that influence the value the network focal delivers its end-customers are identified. A central principle in the analysis is that the network contains roles or functions as nodes not specific organisation names. This way it is possible to carry out the analysis without attaching the analysis into existing structures. This is an important aspect in avoiding path-dependent thinking. Another approach to future-oriented analysis of business models and business ecosystems is presented in Ahokangas et al. (2012). This approach aims at developing new business models for companies. The analysis starts from identification of the key actors and analysis of their needs and benefits in the business ecosystem. Second stage of the analysis is to generate scenarios for the identified ecosystem, so that new business models can be created.

In section 3.2, we present our approach for outlining prospective value chains in the context of transport energy systems, which incorporates elements from the above mentioned approaches. Central aspects in our approach are value network thinking and future anticipation based on scenario approach. 


\section{Method}

\subsection{Energy and transport in MLP framework}

Transport and energy systems, international, national or local, relates closely to the definition of large technological systems: 'Technological systems contain messy, complex, problem solving components. They are both socially constructed and society shaping' (Huges 1987).

Figure 2 presents the three basic components of the transport system: users, vehicles and transport infrastructure. In addition, in the middle of these components, all of which interact with one another, are illustrated a fourth and a fifth components: transport services and transport system organisation, governance and regulation. Each of these components is then further elaborated into some key elements that characterise them. For example, transport vehicles and other means of transport rely on alternative technologies and materials, and besides the manufacturing processes, these require also maintenance. Different vehicle solutions make use of different fuels and other energy carriers, and they result in environmental impacts. Furthermore, the use of vehicles involves behavioural and business models, and different types of solutions are available concerning issues such as vehicle ownership (adapted from Auvinen and Tuominen, 2012).

The illustration presents also the main elements of the energy system (primary energy sources, production and storage), which are linked to the transport system mainly through energy and transport infrastructures and are crucial for transport operations.

The transport and related energy system components and elements in Figure 2 can be analysed against the multi-level perspective (Geels 2004). The three levels adjusted to the transport domain are landscape, transport system and technologies and solutions. The components and elements are positioned on the most appropriate levels to indicate their main application areas, but it should be acknowledged that there are no clear boundaries in here. This structuring is supported by the recent work by Geels (in press), where similar early steps in exploring multi-level perspective in the study of transitions in the transport sector are taken. Geels suggests very similar definitions when drafting the automobility system in the context of multilevel perspective when studying transitions towards low-carbon futures. Multi-level perspective in structuring the socio-technical system for land-based road transport has also been used by van Bree et al. (2010). In their work, hydrogen and battery-electric vehicle scenarios were mapped when taking the relationship between car manufacturers and consumers into focus. 


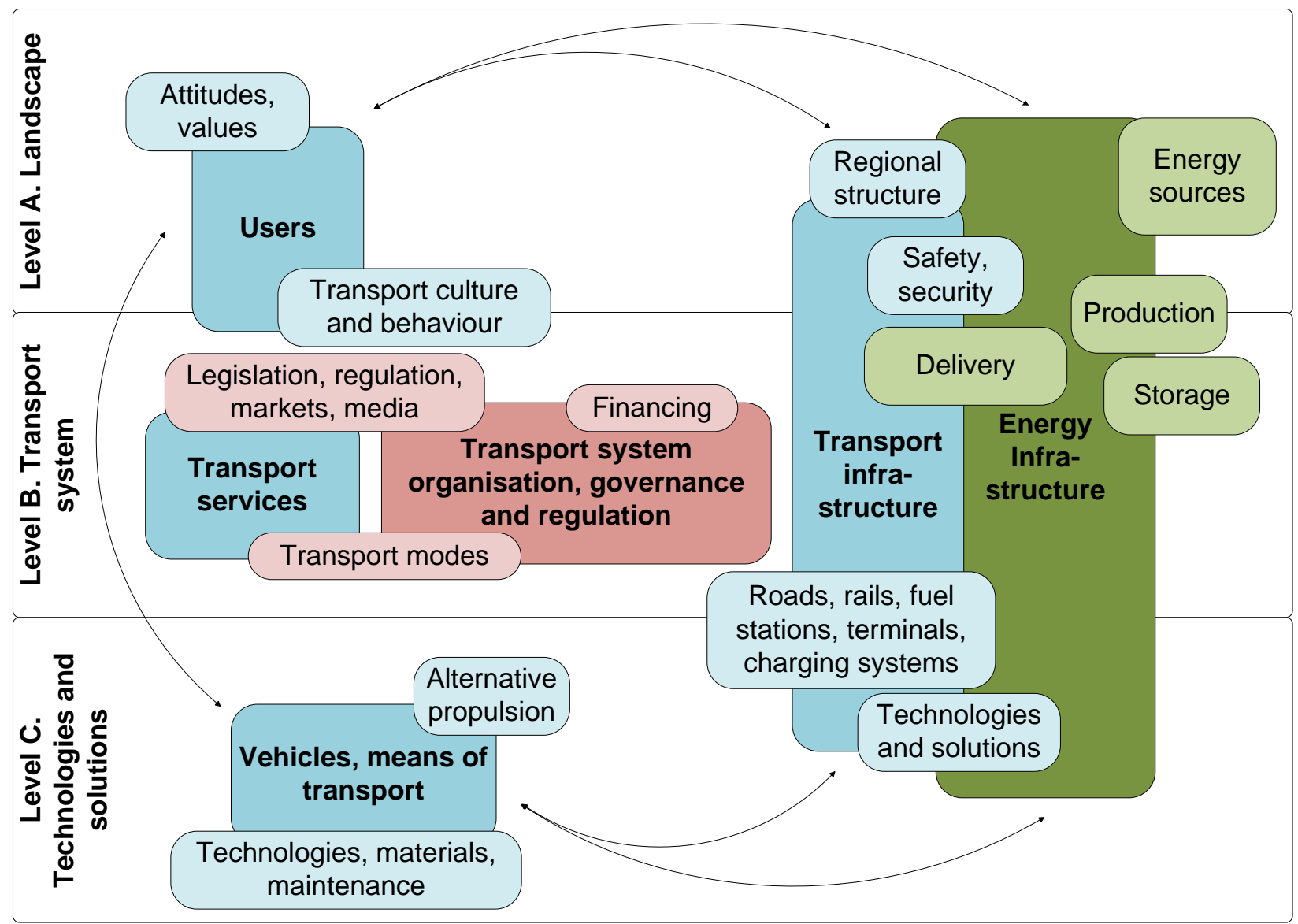

Figure 2. The basic components of transport and related energy systems against multi-level perspective.

The state of the transport system is a result of the measures and actions carried out by the producers, operators and users of the system. Producers and operators are organisations or companies, which can be categorised according to their main duties, such as: policy formulation, infrastructure construction and maintenance, production and operation of services for the transport system, and production of transportrelated services (e.g. vehicle manufacturing and fuels). Individual people, actually the whole population, are the users of the passenger transport system. In freight transport, users are companies and organisations in the fields of industry, transport and commerce (Tuominen et al. 2007).

Producers gather information on the state of the transport system and also receive feedback from customers, that is, the users of the transport system. They make plans on the grounds of expert knowledge (design principles), and decisions based on generic or special decision-making principles. Within the process, information about the system gathered by the producers is, or at least should be, transformed into policy measures, aiming to lead the transport system into a desired, sustainable future (e.g. Richardson, 2005, Steg et al. 2005, Tuominen et al., 2007). 


\subsection{An approach for outlining Prospective Value Chains for sustainable energy systems in road transport}

This section propeses an approach for outlining prospective value networks for sustainable energy systems in road transport. The approach enables participative foresight and supports sustainable policy making. The procedure consists or three stages (see Figure 3):

Step 1: Building future context for the prospective value chains

Step 2: Identification of value network actors

Step 3: Outlining of the prospective value networks

The starting point of the process (Step 1) is to create an idea of the context were the prospective value networks will operate. For this pourpose, various foresight methods, such as Futures Wheel (Glenn 1994), and scenario methodology (e.g. UNIDO 2005) can be used. The purpose of the futures whees is to open future thinking and help the recognition of key factors or drivers, which affect the future develoment of energy and transport systems. Based on the futures wheel exercize, it is possible to create alternative futures using scenario methodology. The alternative futures create alternative possibilities for different technology platforms to develop. To be able to anticipate the technological development in different futures, the strengths, weakneses and develoment possibilities of the different technology platforms need to be analysed. The analysis phase consists of SWOT analysis of the technology platforms and evaluation of the scenarios from the perpective of various technologies. The goal of the first step of the procedure is to recognize the ideal future for each technology platform. In other words, this enables the identification of the factors, which support the development of single technology platrom the most. By doing so, it is possible to use backasting approach to formulate policy recommendations about what kind of actions are needed to acheve the desired future. 


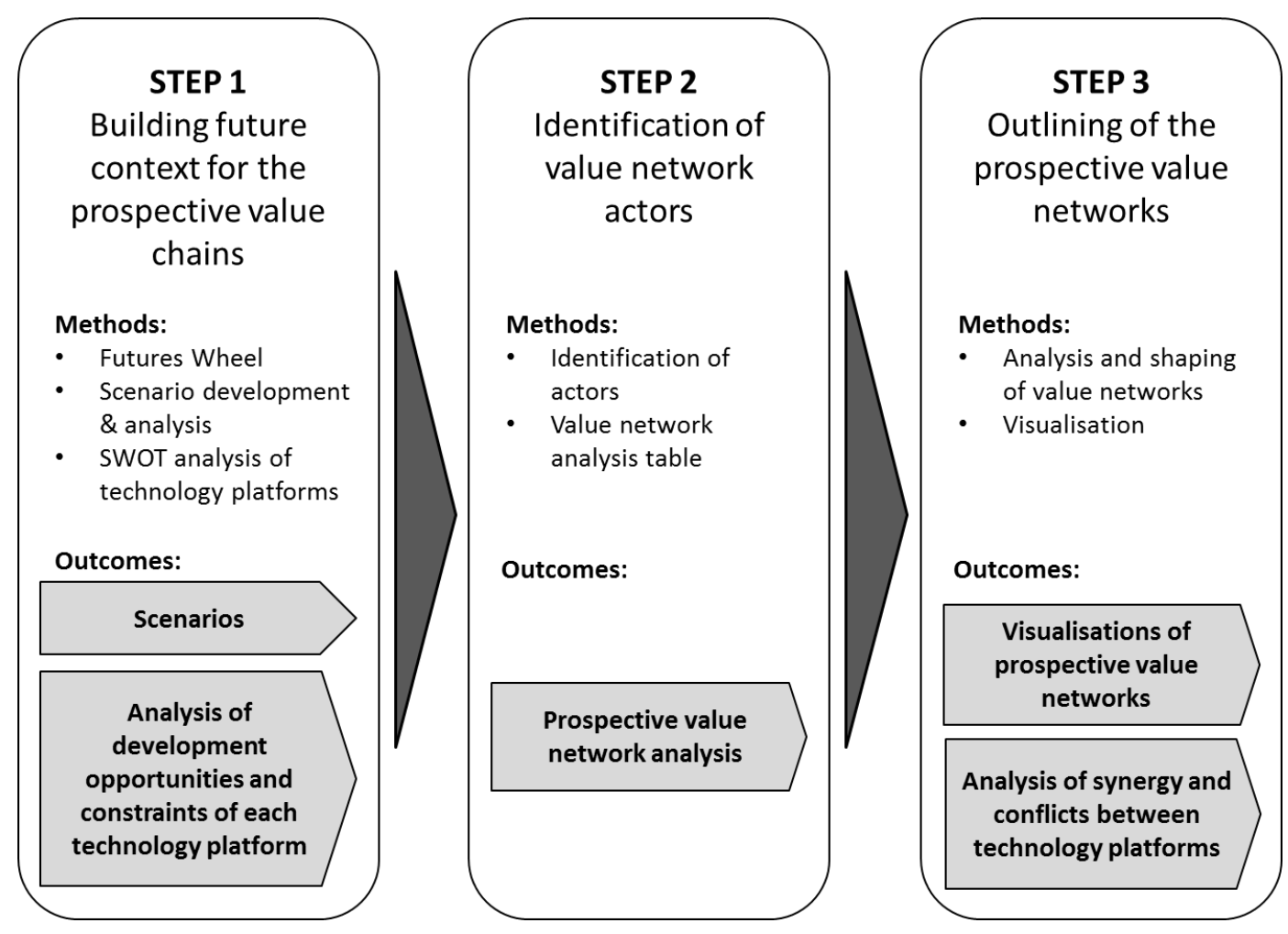

Figure 3. A procedure for prospective value chain analysis.

The goal of the second step is to identify the value network actors and analyse their individual interests, and connections between different actors. The analysis covers value chain activities from energy sources and feedstock production to energy production, distribution and transport, retail and consumption. Also regulation, governance and R\&D actors are included in the analysis. First, all possible actors are listed and then their opportunities and advantages, as well as supportive needs are analysed. Opportunities refer to the possibilities to make profit in the value network (How the actor benefits from the value network?), and advantage refers to created value by the actor (What is the added value the actor produces to its customer or in the network?). The analysis of the supportive activities is needed to recognize the connection between different actors.

Based on the material produced in the second step, it is possible to move to the third stage, which includes outlining of the prospective value chains. In this stage, couple of aspects need to be taken into consideration. Different technology platforms will co-exist in the future, but as was mentioned above, different futures create different opportunities and development possibilities for different technology platforms. Therefore, one needs to describe the level of technological development of the given technology platform in the outline of the value network. In other words, the outline of the value network works only in selected scenario, and the level of technological development of a single technology platform is different in different scenarios. Another important factor is to consider the customer or transport segment of the value network. This refers at least to two different aspects. First, road transport can be divided into transportation of people or goods. Secondly, different technologies are feasible in different distances, e.g. in low-distance daily commuting or long-distance travel or goods transport. In addition to the characteristics of the transportation act itself, also the customer, i.e. weather it is private person or public actor, may affect the value network operations. Therefore, these aspects need to defined separately for each value network outline. Finally, a suitable format of visualisation of the prospective value networks can be selected. 
The following section of this paper presents an illustrative example of the usage or the procedure in the TOP-NEST project. The example is based on the workshops and literature surveys carried out in the project. It is necessary to note that the project is still in progress, and the procedure is not carried out to the very end. The first step is fully covered, and the second one in some extend. The Third step of the procedure is not covered here, as the final results will be based on workshops which will be carried out in the forthcoming months.

\section{An Illustrative example on the use of the procedure}

\subsection{Building future context for the prospective value chains}

The first step in the procedure for outlining the prospective value networks is to build future context the development. To do this we organized a group brainstorming session using Futures Wheel as an aid. Based on the futures wheel exercise (see Figure 4), the following three future directions were recognized:

1. "Green energy and transport": Environmentally sound transport system, which is resulting from strong environmental regulation and policy making.

2. "Co-existence of technologies": Various technologies co-exist in the transport system due to each one's limitations and advantages. A key driver in this line is technological development.

3. "Changing values as a base for new transport system": Changing values are the main driver for change and new transport solutions are developed to meet new needs.

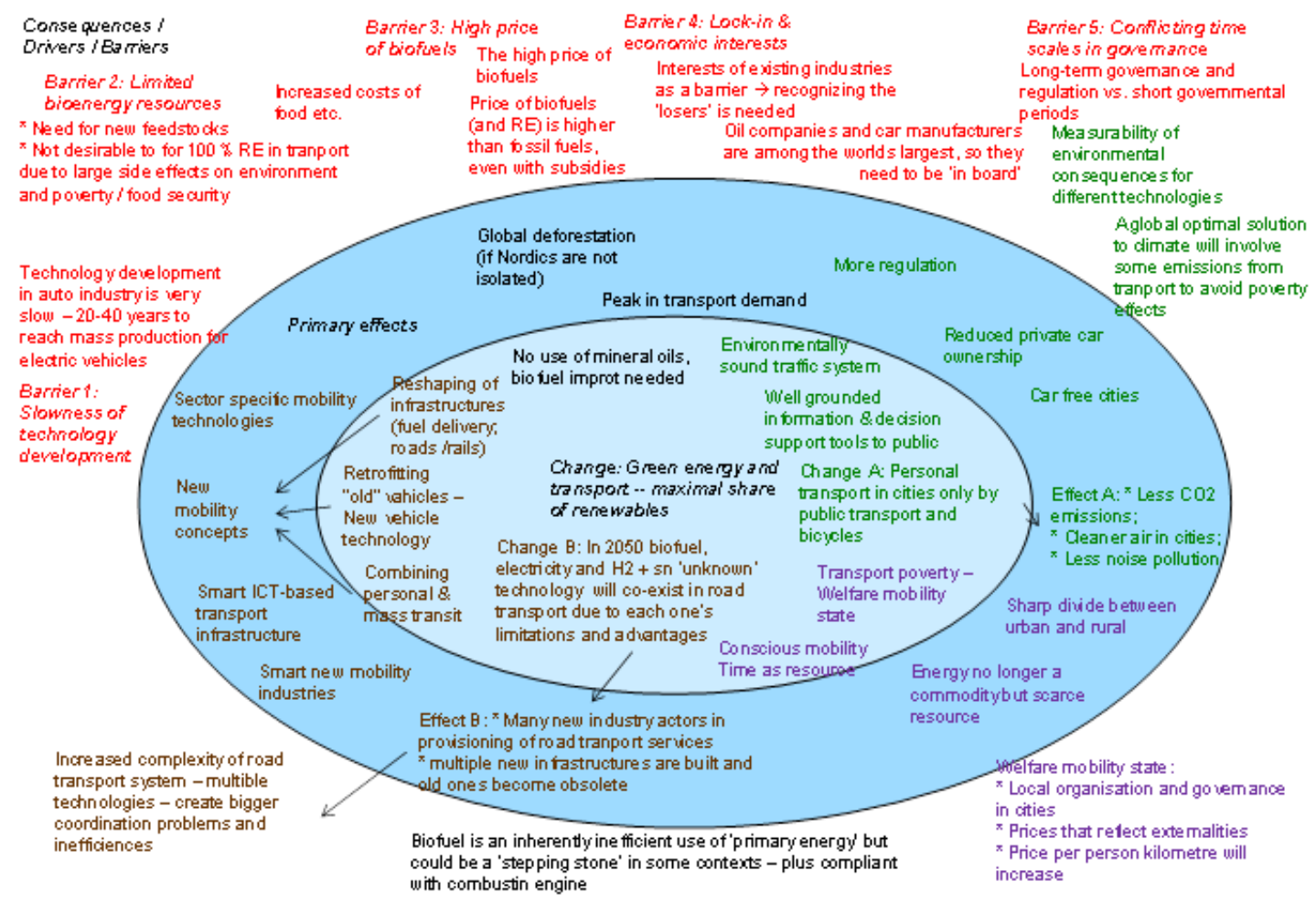

Figure 4. Futures wheel produced in the project workshop. 
To formulate scenarios, we needed two factors which cover the above mentioned directions. This comes to a question about the time required for the societal transition. It can be assumed that if the society as a whole works for the same direction, the transition is smoother and takes shorter time. On the other hand, if there are lot of conflicting interest and no common goals in the society, the transition is slower. We described this aspect by policy coherence factor. On the top of the diagram ( $\mathrm{Y}$-axis in figure $\mathrm{z}$ ), there is coherent, sustainability goal oriented transition policy, and in the other end incoherent or fragmented policy making. The other dimension of the scenario building ( $\mathrm{X}$-axis) connects the examination to the context of transport. Societal structure, weather it is decentralized (on the left side) or centralized (on right), affects the transport volume. However, we interpreted this dimension also in wider sense to cover certain operational logic so that in centralized society, for example, big firms dominate production and in the decentralized alternative local and small scale production is preferred. Using the framework presented in Figure 5, we formulated four different scenarios for 2050, which are described briefly below.

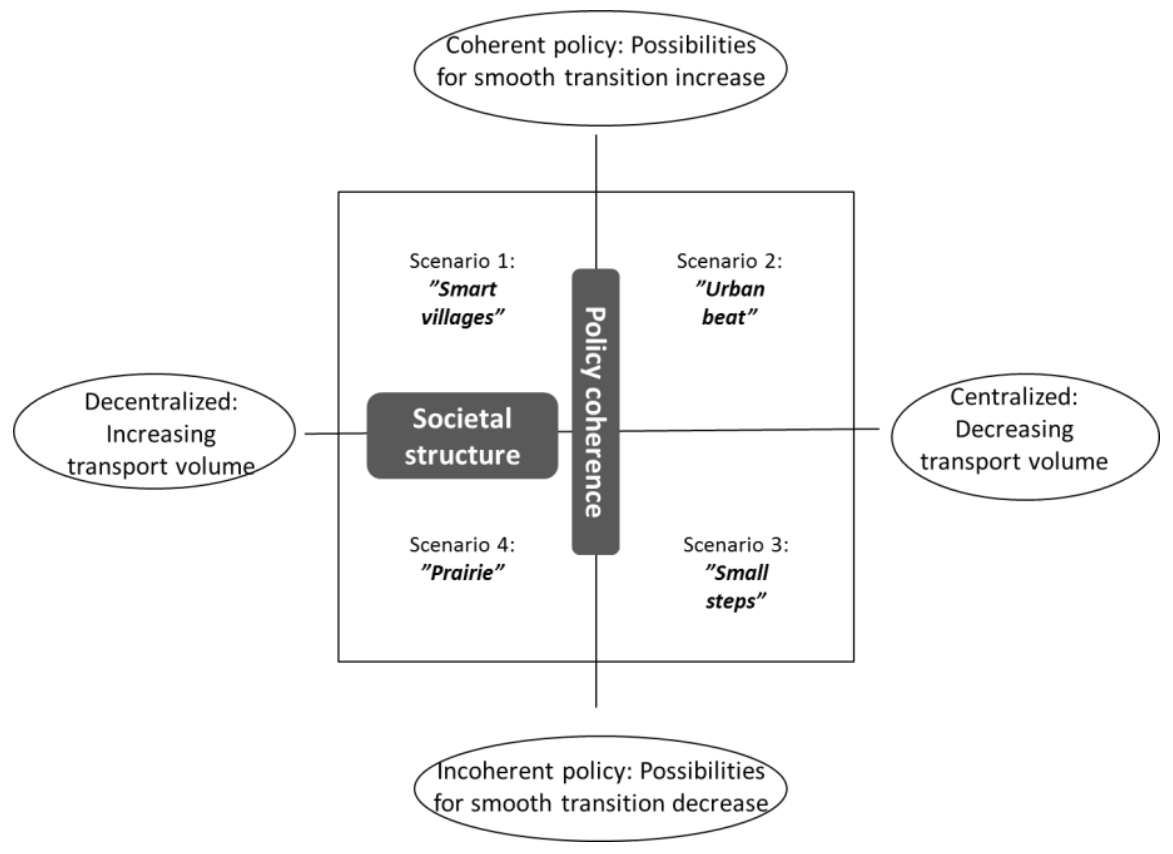

Figure 5. The principle of scenario creation and the four transport scenarios formulated for 2050.

\section{SMART VILLAGES - Decentralized community structure and energy system \& coherent policies}

Road transport is a dominant mode for both passenger and goods transport. Smart, low carbon public and goods transport solutions for small communities are deployed and attracting more users. Community based thinking and acting is strong, but it does not prevent generation of private passenger transport. Slight increase in passenger transport demand has taken place, but the demand for transportation of goods has decreased. Technological development is on a moderate level. Industries and services are mainly locally based. Public, private and research organisations have built up strong local or regional clusters for cooperation and decision making. Powerful local, regional and national regulations and incentives steer vehicle and fuel production, distribution and use. 


\section{URBAN BEAT - Centralized community structure and energy system \& coherent policies}

Due to the centralised community and energy system structures, rail transport and non-motorised transport (cycling, walking) dominate in cities. For long distance travel and transportation of goods, high-speed rails are the main transport mode. Urban regions have seamless, just-in-time, public transport and urban logistics services. Transport system end-users consider green, renewable energy production and transport as a fundamental value of the society. Substantial decrease in transport demand has taken place.

Technological development is fast and large service sector companies have reconstructed the industrial structure. Public, private and research organisations at national and Nordic levels have built up strong urban clusters for co-operation and decision making. In addition, powerful, complementing global and EU regulations and incentives steer vehicle and fuel production, distribution and use.

\section{SMALL STEPS - Centralized community structure and energy system \& incoherent policies}

Various modes of transport, such as road, rail and NMT are used in cities without clear priorities. Road transport dominates long distance travel and transportation of goods. Both private and public transports are supported, but no clear decision on preference has been taken. End-user views and needs towards energy and transport are dispersed. Passenger transport demand has decreased slightly, but in transportation of goods, there is no evident change. Centralised energy intensive industries form the industrial back bone. Technological development is moderate due to lacking coordination of R\&D activities and cooperation between public and private research organisations. Various (even conflicting) regulations, incentives on fuels and vehicles, their production and distribution have been prepared and realised.

\section{PRAIRIE - Decentralized community structure and energy system \& incoherent policies}

Due to the decentralised community and energy system structures, road transport is the dominant mode for both passenger and goods transport. However, the development and maintenance of road network is poor. In the absence of common vision and co-operation networks, public transport is slowly fading away. The overall economic situation is bad, travelling and transportation of goods is expensive and hence transport demand decreases. The state of energy intensive industries is poor, because no renewal has taken place. Also, technological development is slow. Public, private and research organisations have very little cooperation. Each organisation tries to survive individually. Only few poorly supervised regulations and incentives on vehicle and fuel production, distribution and use have been carried into effect.

After the alternative scenarios were developed, they were analysed from the perspective of the three technology platforms. This analysis task can be approached from two directions. First, one needs to analyse the technology platforms to recognize their strengths, weaknesses, threats and opportunities. For this purpose, we carried out SWOT analysis of each technology platform. Results of the SWOR analyses are presented below. After the strengths and weaknesses of the technology platforms were identified, it was possible to analyse the scenarios to explore the benefits and challenges each scenario create for the technology platforms.

A clear strength of biofuels is that from technological perspective it is compatible with the existing energy and transport infrastructures. The existing infrastructure of fuel production, storage and distribution is suitable for biofuels. Also, existing cars can in large amount use bio fuel. Another strength is the wide variety of raw-material options. If we take into account both $1^{\text {st }}$ and $2^{\text {nd }}$ generation biofuels, possible raw 
material can be found form agro biomass, forest biomass and different kind of industrial and municipal waste. However, the logistics of biomass raw material may be complex and costly to arrange. In Nordic countries, there is an existing forest industry based logistic system, which can be applied on biofuel system. Waste collecting systems are also well developed. Raw material options based on industrial waste give opportunities for the development of industrial symbiosis systems (closed systems, closed material flows also across companies). Rather low conversion efficiency diminishes the potential of biofuels. It is not efficient to transport biomass raw material for long distances, because of high water concentration of raw material. Therefore biofuel production is most feasible in distributed and local modes of operation. Globally, biomass raw material is scarce natural resource and emerging bio economy has also other competing uses for biomass. Biofuels can also struggle space for food industry; consumers do not want to use food as fuel. Unsustainable production of biofuel raw material is seen as a threat to the biodiversity and global food production (scarcity of food production land). A heavy certification schemes are needed in order to secure the sustainable production, which is costly.

Strength of electricity platform is that it is based on existing and efficient general purpose technology, which is already partly renewable. However, not all electricity is renewable and therefore the environmental soundness of electronic vehicles (EV's) is dependent on the production profile of given electricity market. Electronic vehicles are not yet in mass production. A weak point in the technology development is batteries. They are expensive and full electronic vehicles have short range and therefore they cannot replace existing cars in all uses. However, there are available various hybrid solutions, which provide more robust operation and energy security in daily use. For heavy duty, electricity is not an option, unless some "e-highway" solution is developed. In this case, transportation would be vulnerable to power disruptions. The diffusion of EV's may be slow due to high investment costs. Consumers need to invest in new vehicles and communities in the operational preconditions of electronic transport. Power grid exists already, but the link from grid to consumer need to be established. The main technology developers (car producers and electric utilities) are big companies, and therefore they have good resources for development. However, there is a clear lack of cooperation between automobile industry and electric utilities. There are good supportive mechanisms and promotional tools to establish a market for EVs (e.g. tax reductions, own lanes for electric cars). Some of the mechanisms are feasible based on local ordinances, which makes it possible to promote EVs also locally in one city or region. So far, the use of policy instruments for accelerating the market has been strong in Norway, not in other Nordic countries. When promotional policies are stopped, it may cause a market disruption.

Hydrogen has several strengths from technological point of view. There are multiple sources available for hydrogen ( $\mathrm{H} 2$ ) production, in addition, $\mathrm{H} 2$ is already a by-product from some industries. Hydrogen may also provide flexibility to the energy system (in reserve power regulation). In transport, hydrogen (fuel cell, FC) cars provide respectable alternative to contemporary private car in terms of driving range. The need of $\mathrm{H} 2$ for biofuel and electro fuel production provides great opportunities in the future. On the other hand, there are also several weaknesses. Platinum and/or similar type of noble metals, which are usually used as the catalysts for FCs are limited resources, very expensive and hence provide price risk for FC production. Also production of carbon free $\mathrm{H} 2$ is currently very expensive. Consequently, all industrial and trade activities relating to FCs include large economic risks. For private houses, farms, etc. hydrogen can be seen as a potential back-up power in the future. $\mathrm{H} 2$ (storage) may still pose a threat of safety (explosion), which evokes (bad) publicity. Today, hydrogen technology development suffers from lacking knowledge and shortage of educated people. There are only few stakeholders on the market and "backlash" of hydrogen hype prevails. Hydrogen gives a possibility to implement strict $\mathrm{CO} 2$ regulation since $\mathrm{H} 2$ makes it possible to 
create $100 \%$ renewable energy production. Further, hydrogen's flexibility increases potential to reach consensus among different stakeholders. Currently, there are not enough mandatory standards for hydrogen which is a weakness. Different views of Nordic countries on future opportunities of hydrogen and over/underspecified $\mathrm{H} 2$ quality may cause high costs and bad user experiences, which pose threats for the future.

Table 1 summarises the results of the scenario analysis. The aim of the analysis is to recognise, which scenarios are the most beneficial for each technology platform. It can be assumed that this technology platform would be in a dominating position if the very scenario came true. On the other hand, to be able to formulate some policy advice, it is important to identify the challenges other technology platforms would meet in these scenarios. For example, the characteristics of biofuels and hydrogen technology are in line with the decentralized structure and demand for local solutions of the "Smart villages" scenario. On the other hand, the same demands create a challenge for electricity, as they result in high need for energy storages and adjustment power. Biofuels are also strong in the "Small steps" and "Prairie" scenarios, because they are compatible with the existing energy and transport structures, and therefore they can evolve even if there is shortage of R\&D investments or shared objectives in the technology development.

Table 1. The results of the scenario analysis.

\begin{tabular}{|c|c|c|}
\hline Scenario & $\begin{array}{l}\text { Dominant technologies } \\
\text { (benefitting from the } \\
\text { circumstances) }\end{array}$ & Challenges for other technology platforms \\
\hline Smart villages & $\begin{array}{l}\text { Biofuel } \\
\text { Hydrogen }\end{array}$ & $\begin{array}{l}\text { - Goods transport is based on road transport, which is } \\
\text { challenging for electricity } \\
\text { High need for energy storages and adjustment power to } \\
\text { guarantee the availability of electricity in the decentralized } \\
\text { society }\end{array}$ \\
\hline Urban beat & Electricity & $\begin{array}{l}\text { - Small volumes for biofuels, because electrification of society is } \\
\text { emphasized } \\
\text { - Advancing bio economy creates competing uses for biomass } \\
\text { (decreasing transportation volume may compensate this) } \\
\text { - Possible shortage of R\&D investments } \\
\text { - No demand for long distance electric passenger traffic } \\
\text { (challenge for hydrogen) }\end{array}$ \\
\hline Small steps & Biofuels & $\begin{array}{l}\text { - Contradicting interests hinder the development of public } \\
\text { transport and its electrification } \\
\text { - No coherent regulation or coordinated development activities } \\
\rightarrow \text { Companies are not willing to develop technology } \\
\text { - Organisation of heavy road transport is very challenging for } \\
\text { electricity and hydrogen }\end{array}$ \\
\hline Prairie & Biofuels & $\begin{array}{l}\text { - Global economic crisis delays development, no money for } \\
\text { implementation of new technologies } \\
\text { - Disintegration of the infrastructure (challenge for electricity) }\end{array}$ \\
\hline
\end{tabular}

The next section shows an illustrative example of the analysis of value network actors based on biodiesel. 


\subsection{An example of analysed value network actors - a biodiesel case}

In the TOP-NEST project we have made among other case-studies a description about the $2^{\text {nd }}$ generation biodiesel process based on written material and interviews. In this paper we illustrate the use of our prospective value network analysis procedure using the case description as a source material. For proper testing of the procedure, we are going to organize a stakeholder workshop later in the TOP-NEST project. The invited stakeholders will represent industry, ministries, NGO's including nature protection organisations and other relevant interest groups, such as vehicle industry and bioenergy associations, and researchers. An alternative method to gather information would be to interview the stakeholders.

Our case-company has started to develop its biofuel business by building a hydro-treatment based biorefinery next to the pulp mill of the company, which will use crude tall oil as a primary raw material. The hydro-treatment biodiesel biorefinery investment is made without any public subsidy. It is the first marketoriented hydrogen treatment biorefinery in the world. The total investment of the plant will be 150 MEUR. The plant will employ totally (direct and indirect) about 200 persons. The investment decision was made in February 2012, building started in the summer 2012 and production will start in 2014.

The chosen case-study corresponds to the "Small steps" scenario, as it would describe a situation, where a forest industry company is refocusing its business. Drivers for this redirection are the dramatic decrease of the demand of traditional forest products and global monetary crisis. At the same time, there is a global need for increasing the use of renewable energy in road transport. In these circumstances, the production of biofuels is a tempting path for a forest company to follow. One could say that this case-study is strongly path dependent example. The biorefinery company has long forest industry history in Finland. The first mechanical pulp mill, paper mills and sawmills started operations in the early 1870 . Pulp production started in 1880. An important strategic goal is to start to produce $2^{\text {nd }}$ generation bio fuels from wood material. Since the company is a traditional forest industry company, the production of $2^{\text {nd }}$ generation biofuel continues nicely its history. Tall oil is produced from black liquor soap, a side flow of sulphur-chemical pulp mill process. In theory, other bio-oils and fats, Fischer-Tropsch wax, black liquor, lignin, turpentine and pyrolysis oil from forest biomass could also be used in the process. The same fuel distribution system can be used as used in fossil fuel distribution.

The first step in the analysis of the prospective value network is to identify the actors which construct the network. As we are developing the biofuel case, the natural network focal is the tall oil producer (see figure 6). The network shows the relationships between different actors. After the network structure is constructed, it is possible to analyse the value creation potential of the connections. This analysis may reveal new potential relationships or ways to organise the value chain structures in the future. For instance, the biorefinery company or the tall oil producer may develop to technology supplier in the future, as they own the intellectual property rights to their process. Another example of the possible findings based on the value network chart is that there may be changes in the delivery part of the value network. For example, some heavy users of biofuels might get the fuel straight from biodiesel producer instead of various intermediary actors. The network analysis reveals also that tall oil based biodiesel production requires pulp production to be profitable. In addition, to be able to use this biodiesel option, we need liquid fuel distribution system and vehicle industry in favour of biodiesel as an energy source for road transport. It is necessary to note that these suggestions are only illustrative examples. The real future oriented analysis will take place in the later phase of the TOP-NEST project. 


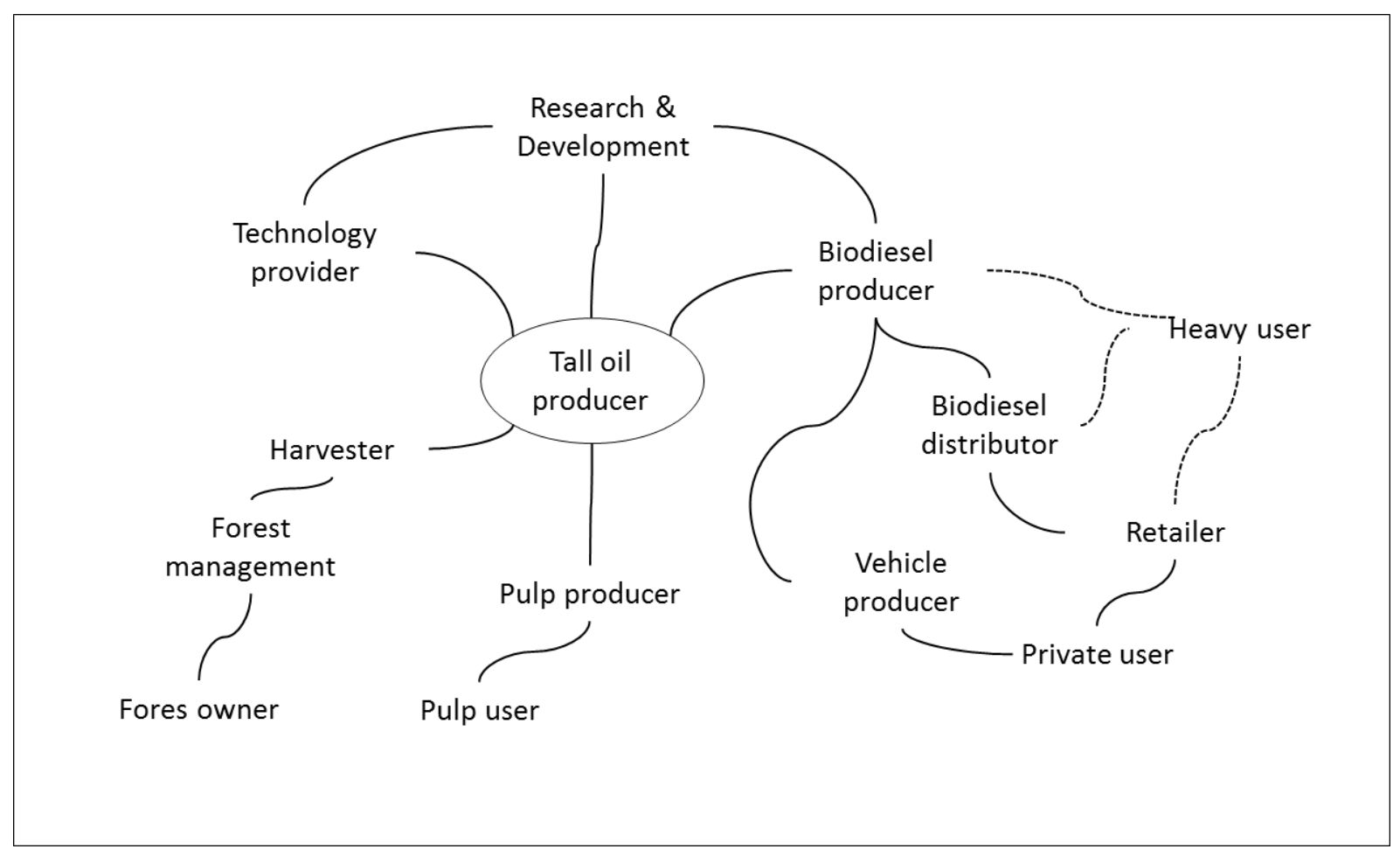

Figure 6. Value network of a biodiesel example based on tall oil.

The value network chart is a base for analysis that is needed to outline the prospective value chains or networks. In other words, it gives information about the possible futures (landscape level constraints and niche options) and the needs of commercial actors to be able to operate in the future's world. This information can be used to formulate policy guidance in order to define the prerequisites of the needed regime construction. For example, the figure 6 clarifies that if biodiesel production is based on tall oil production, we need pulp mills in order to produce tall oil, and this aspect makes global pulp markets an important constraint for biodiesel production. In the tall oil based biodiesel case the path dependency of the production process conducts political decisions to maintain the existing regime where tall oil production is profitable.

\section{Discussion and conclusions}

In this paper we have proposed an approach to outline prospective value chains in the road transport of the Nordic countries in $\mathbf{2 0 5 0}$ context. The starting point for our analysis was that future value chains and future actors within have to be recognised in order to find out prerequisites of the future actions related to renewable energy sources for transport. Identification of key actors is important since they are responsible on the decisions towards low carbon futures.

The proposed approach may act as a checklist for the important things to be covered in outlining prospective value chains in the road transport context. For instance all the value chain activities should be discussed to find out the important points, from the point of view of actors and value creators in the network.

The process integrates methods from different theoretical starting points, namely the foresight and value chain theories. It also integrates energy and transport systems, and expands the context far to the future. 
The process is not yet complete but the work will continue in the TOP-NEST project up to the end of year 2013.

To outline future actors is a challenging task. At this stage of the process development we have noticed that the most challenging part in this task is first to be able to imagine potential new actors and second to create potential new relationships between the actors. Especially this task is difficult in a strongly path dependent situation, as is a biodiesel case. We assume that for instance in testing this procedure in hydrogen technology system the challenge may be slightly easier, because for instance in Finland the current hydro technology actors are very few.

Another huge challenge is to get relevant stakeholders to either participate the workshops or give interviews. Stakeholders may be too busy or tired to participate workshops, which are quite usual methods used in today's research and business world. . At least in this road transport context, the issue to be discussed is so large including energy, transport and transition policies, that the discussion would take time if done properly. There may also be confidentiality problems concerning new emerging technologies; stakeholders do not want to participate public discussions

A challenge is also to look at different technological platforms, biofuels, hydrogen and electricity, at the same context in order to find synergies between them. In real world it is not realistic to depend on only one option, but different technological solutions are available simultaneously.

Despite all the challenges we have faced in this process we still believe that the prospective value network analysis helps us to figure out landscape level constraints, like values and global trends, niche level options, as well as the needs which guide us to change or maintain the existing regime in order to achieve the goals, such as renewable energy use. One way of changing the regime is to make political decisions. Value network analysis gives us views about the future and about the potential paths and constraints to help making wise political decisions.

\section{References}

Ahlqvist, T., Valovirta, V., Loikkanen, T. (2012) Innovation policy roadmapping as a systemic instrument for forward-looking policy design. Science and Public Policy 39 (2012), pp. 178-190.

Ahokangas, P., Matinmikko, M., Myllykoski, J., Okkonen, H. (2012) Future scenarios, ecosystems and business models for cognitive radio systems. VTT Technology 55, VTT:Helsinki, $54 \mathrm{p}$.

Auvinen, H. \& Tuominen, A. 2012, Safe and secure transport system 2100. Vision. VTT Technology 5 (2012).

Bolwig, S., Ponte, S., Du Toit, A., Riisgaard, L., Halberg, N., 2010. Integrating Poverty and Environmental Concerns into Value-Chain Analysis: A Conceptual Framework. Development Policy Review 28 (2), 173194. 
Coe N.M., P. Dicken, and M. Hess. (2008). Introduction: global production networks-debates and challenges. Journal of Economic Geography 8, 267-269.

Da Costa, O., Warnke, P., Cagnin, C., Scapolo, F. (2008) The impact of foresight on policy-making: insights from the FORLEARN mutual learning process. Technology analysis \& Strategic Management, vol. 20, No. 3, pp. 369-387.

Eriksson, A., Weber, M. (2008) Adaptive Foresight: Navigating the complex landscape of policy strategies. Technological Forecasting \& Social Change, vol. 75, pp. 462-482.

Foxon, T.J., Hammond, G.P. \& Pearson, P.J.G. 2010, "Developing transition pathways for a low carbon electricity system in the UK", Technological Forecasting and Social Change, vol. 77, no. 8, pp. 12031213.

Geels, F.W. 2005, "Processes and patterns in transitions and system innovations: Refining the coevolutionary multi-level perspective", Technological Forecasting and Social Change, vol. 72, no. 6, pp. 681-696.

Geels, F.W. \& Kemp, R. 2007, "Dynamics in socio-technical systems: Typology of change processes and contrasting case studies", Technology in Society, vol. 29, no. 4, pp. 441-455.

Geels, F.W. \& Schot, J. 2007, "Typology of sociotechnical transition pathways", Research Policy, vol. 36, no. 3, pp. 399-417.

Geels, F.W. 2012, A socio-technical analysis of low-carbon transitions: introducing the multi-level perspective into transport studies. J. of Transp. Geography 24 (2012) 471-482.

Georghiou, L., Keenan, M. (2006) Evaluation of national foresight activities: Assessing rationale, process and impact. Technological Forecasting \& Social Change, vol. 73, pp. 761-777.

Gereffi, G. (1994) 'The Organization of Buyer-Driven Global Commodity Chains: How US Retailers Shape Overseas Production Networks', in G. Gereffi and M. Korzeniewicz (Eds.) Commodity Chains and Global Capitalism. Westport: Greenwood Press.

Gereffi, G., Humphrey, J. and Sturgeon, T. (2005) 'The Governance of Global Value Chains', Review of International Political Economy 12 (1): 78-104.

Gibbon, P., Bair, J. and Ponte, S. (2008) 'Governing Global Value Chains: An Introduction', Economy and Society 37 (3): 315-338.

Glenn, J.C. (1004) The Futures Wheel. AC/UNU Millennium Project. Futures Research Methodology. [CD-rom].

Hughes, T.P.(2007) The evolution of large technological systems in Bijker, W.E., Hughes, T.P., and Pinch, T. (Eds.): The social construction of technological systems. New directions in the sociology and history of technology, MIT Press, Massachusetts, 1987, pp. 51-82.

Humphrey, J. and Schmitz, H. (2002) 'Developing Country Firms in the World Economy: Governance and Upgrading in Global Value Chains', INEF Report 61/2002, University of Duisburg. 
International Energy Agency, Nordic Energy Research. 2013. Nordic Energy Technology Perspectives. Pathways to a Carbon Neutral Energy Future, 204 p. www.iea.org/etp/nordic

Kaplinsky, R. (2000) 'Spreading the Gains from Globalization: What can be Learned from Value Chain Analysis?' IDS Working Paper 100. Brighton: IDS.

Koljonen, T., Similä, L. (eds.). 2012, Low Carbon Finland 2050. VTT Clean energy technology strategies for society. VTT Visions 2, 75 p. 2012.

Könnölä, T., Scapolo, F., Desruelle, P., Mu, R. (2011) Foresight tackling societal challenges: Impacts and implications on policy-making. Futures vol. 43. pp. 252-264.

Normann R. \& Ramirez, R. (1994). Designing Interactive Strategy: From the Value Chain to the Value Constellation, John Wiley \& Sons, Chichester.

Peppard, J. \& Rylander, A. (2006). From Value Chain to Value Network: Insights for Mobile Operators, European Management Journal, Vol. 24, Nos. 2-3, pp. 128-141.

Ponte, S. and P. Gibbon (2005) 'Quality Standards, Conventions and the Governance of Global Value Chains', Economy and Society 34 (1): 1-31.

Ponte, S. (2007) 'Governance in the Value Chain for South African Wine', TRALAC Working Paper 9/2007. Stellenbosch: Trade Law Centre for Southern Africa.

Richardson, B. (2005) Sustainable transport: analysis frameworks. J. Transport Geogr., 2005, 13, (1), pp. 29-39.

Riisgaard, L. (2009) 'Global Value Chains, Labour Organization and Private Social Standards: Lessons from East African Cut Flower Industries', World Development 37(2): 326-340.

Steg, L., \& Gifford, R. (2005) Sustainable transportation and quality of life. J. Transport Geogr., 2005, 13, (1), pp. 59-69.

Sturgeon T., J.V. Biesebroeck, and G. Gereffi. (2008). Value chains, networks and clusters: reframing the global automotive industry. Journal of Economic Geography 8, 297-321.

Tuominen, A., Järvi, T., Räsänen, J., Sirkiä, A. and Himanen, V. (2007) Common preferences of different user segments as basis for intelligent transport system: case study - Finland. IET Intell. Transp. Syst., 2007, 1, (2), pp. 59-68.

UNIDO (2005) Unido technology foresight manual, Volume 1 Organization and methods. United Nations Industrial Development Organization, Vienna. 246 p.

Weber, M., Kubeczko, K., Kaufmann, A., Grunewald, B. (2009) Trade-offs between policy impacts of future-oriented analysis: experiences from the innovation policy foresight and strategy process of the city of Vienna. Technology analysis \& Strategic Management, vol. 21, No. 8. pp. 953-969.

Valkokari, K; Valjakka, T \& Kansola, M (2011) Towards collaborative smart supply chains - capabilities for business development, International Journal of Enterprise Network Management. Vol. 4 (2011) No: $4,380-399$ 
Vitae

Dr. Nina Wessberg is a senior scientist in Foresight and Socio-Technical Change team at VTT. Her current research interests are especially in sustainable energy solutions at the society. She works at the moment as a project manager in two international research projects dealing with renewable energy transition management issues in the eco-city and road transport contexts. She has also been carrying on various roadmap processes. She holds a Dr. Degree in environmental policy and a M.Sc. degree in environmental technology.

Mrs. Anna Leinonen is a research scientist in Foresight and Socio-Technical Change team at VTT. Her research interests include the functions of foresight in socio-technical transitions and policy-making, and foresight methodologies. She works currently as a project manager and project researcher in research projects dealing with these issues in the context of arctic technology and renewable energy transition management. She holds a M.Sc Degree in Automation and control technology and a M.Soc.Sc. degree in Journalism and mass communication.

Dr. Anu Tuominen is a principal scientist at VTT Technical Research Centre of Finland. She holds a D.Sc. (Tech.) in Environmental Strategies, Technology Assessment and Transportation studies from Aalto University, Finland. Her research interests lie in the fields of knowledge production for transport policies, transport system impact assessment, technology foresight and socio-technical change in which areas, she has participated in several national and international research projects.

Dr. Annele Eerola is Principal Scientist in the Foresight and Socio-Technical Change team of VTT Technical Research Centre of Finland. Her research focuses on the links between foresight knowledge, strategy and policy. She has participated in international foresight cooperation and development since the beginning of 2000's, incl. several EU and Nordic projects in the fields of energy and sustainable developments. She holds a doctor's degree (organisation and management) from Helsinki Swedish School of Economics and Business Administration and a Lic.Tech. degree (system analysis) from Helsinki University of Technology.

Dr. Simon Bolwig, PhD, Senior Researcher, Head of Climate Change and Sustainable Development research group, Systems Analysis Division, Dep. of Management Engineering, Technical University of Denmark. Simon does research on climate change mitigation and sustainable development, renewable energy, global value chains, and standards and certifications. 